\title{
Character strengths-based interventions: Open questions and ideas for future research
}

\author{
Ruch, Willibald ; Niemiec, Ryan M ; McGrath, Robert E ; Gander, Fabian ; Proyer, René T
}

\begin{abstract}
Numerous studies have confirmed the effectiveness of character strengths-based interventions for fostering well-being. However, there are still several open questions. The present article discusses some of the most important questions. We review the current body of research and provide ideas and possible future directions on issues such as: Should interventions be generic or personalized? What strengths should be addressed in a strengths-based intervention? What is the role of signature strengths? Do strengths-based interventions change the level of character strengths? How can you justify strengthsbased interventions? We conclude that increasing knowledge has not tempered but rather has heightened the initial high expectations on the important contribution of strengths-based interventions in research and practice, but still much work remains to be done.
\end{abstract}

DOI: https://doi.org/10.1080/17439760.2020.1789700

Posted at the Zurich Open Repository and Archive, University of Zurich

ZORA URL: https://doi.org/10.5167/uzh-189778

Journal Article

Accepted Version

Originally published at:

Ruch, Willibald; Niemiec, Ryan M; McGrath, Robert E; Gander, Fabian; Proyer, René T (2020). Character strengths-based interventions: Open questions and ideas for future research. Journal of Positive Psychology, 15(5):680-684.

DOI: https://doi.org/10.1080/17439760.2020.1789700 
RUNNING HEAD: CHARACTER STRENGTHS-BASED INTERVENTIONS

Character Strengths-Based Interventions: Open Questions and Ideas for Future Research

\author{
Authors
}

Willibald Ruch, Ryan M. Niemiec, Robert E. McGrath, Fabian Gander, René T. Proyer

\begin{abstract}
Author Notes
Willibald Ruch and Fabian Gander are at the Department of Psychology at the University of Zurich, Switzerland. Ryan Niemiec is at the VIA Institute on Character, Cincinnati, USA. Robert E. McGrath is at the School of Psychology and Counseling, Fairleigh Dickinson University, Teaneck, USA. René T. Proyer is at the Department of Psychology at the MartinLuther University Halle-Wittenberg, Germany.

Conflict of interest: Willibald Ruch and Robert McGrath are Senior Scientists for the VIA Institute on Character. Ryan Niemiec is Education Director of the VIA Institute. The VIA Institute is the copyright holder for the VIA Classification.

This publication has been supported by a research grant from the Swiss National Science Foundation (SNSF; grant no. 100014_172723 awarded to WR). Correspondence concerning this article should be addressed to Willibald Ruch, Section on Personality and Assessment, Department of Psychology, University of Zurich, Binzmühlestrasse 14/ Box 7, 8050 Zurich, Switzerland, E-mail: w.ruch@psychologie.uzh.ch
\end{abstract}




\begin{abstract}
Numerous studies have confirmed the effectiveness of character strengths-based interventions for fostering well-being. However, there are still several open questions. The present article discusses some of the most important questions. We review the current body of research and provide ideas and possible future directions on issues such as: Should interventions be generic or personalized? What strengths should be addressed in a strengths-based intervention? What is the role of signature strengths? Do strengths-based interventions change the level of character strengths? How can you justify strengths-based interventions? We conclude that increasing knowledge has not tempered but rather has heightened the initial high expectations on the important contribution of strengths-based interventions in research and practice, but still much work remains to be done.
\end{abstract}

Keywords: character strengths, positive psychology interventions, strengths-based interventions, signature strengths, well-being 


\section{Character Strengths-Based Interventions: Open Questions and Ideas for Future Research}

Character strengths are "positive traits reflected in thoughts, feelings, and behaviors" (Park, Peterson, \& Seligman, 2005; p. 603) that are valued in their own right and contribute to fulfillment. Character strengths-based interventions are interventions that aim at making people aware or encouraging the application of their character strengths in their daily lives to bring benefit to oneself, others, and/or society. Such interventions are well-validated and highly effective for increasing subjective well-being and decreasing depressive symptoms, with emerging support for boosting flourishing (e.g., Schutte \& Malouff, 2018). However, there are several open questions with regard to research and practice. In this article, we discuss some of the most pressing open research questions and provide some recommendations for applied work with strengths.

\section{Should interventions be generic or personalized?}

A worthwhile dimension to consider in the future development of positive psychology interventions has to do with personalized versus generic interventions, i.e., whether treatment should be based on personal data or whether all individuals should receive a common intervention. Personalized medicine, defined as the evidence-based use of patient characteristics to choose among multiple treatment options, is a topic of growing interest. For example, the National Institute of Mental Health (2015) has called for more research on personalized interventions for mental health conditions (see also Ng \& Weisz, 2016).

Of course, all treatment is to some extent individualized, if only in the dosage of medication, or in strategies employed by a psychotherapist during a session. However, strengthsbased interventions differ in the degree to which they inherently require individualization based 
on evidence-based assessment. An intervention that involves writing down three good things that happened involves the same instructions across all participants; one that requires using a signature strength ("strengths that a person owns, celebrates, and frequently exercises" [Peterson \& Seligman, 2004; p. 18]; usually operationalized as the five highest ranking character strengths within an individual) first requires identifying signature strengths for each participant (Seligman, Steen, Park, \& Peterson 2005). An important consideration for research is whether generic treatments differ in effectiveness from treatments that individualize which strengths are targeted. Linkins, Niemiec, Gillham, and Mayerson (2015), for example, have hypothesized that individualizing character interventions in educational settings should result in better outcomes than generic programs, though this hypothesis has not yet been tested. It is noteworthy that Seligman et al. (2005; see also Gander et al., 2013; Mongrain \& Anselmo-Matthews, 2012) found no difference in effectiveness between two treatments representing a generic approach (i.e., writing down three good things) or a personalized approach (i.e., using signature strengths in a new way), suggesting comparable effects of the two approaches. To date, only one study has suggested the potential for personalized strength-based interventions to enhance outcomes. Proyer, Gander, Wellenzohn, and Ruch (2015) found that individuals with generally high scores on strength scales tended to benefit more from an intervention that focused on lesser strengths, while those with more moderate scores benefited more from working on signature strengths.

Focusing on strengths creates a tremendous opportunity for individualizing treatment. We hope future research will explore those opportunities further. Would individuals currently experiencing distress benefit more from a generic intervention focusing on enhancing those strengths most consistently associated with well-being such as zest, curiosity, gratitude, hope, 
love, and humor, or from interventions that encourage greater use of one's signature strengths? A number of such questions can be enumerated.

\section{What strengths should be addressed in a strengths-based intervention?}

When considering generic intervention programs, an important question is what strengths should be trained in order to maximize increases in well-being. The hypothesis that interventions should focus on strengths more strongly associated with subjective well-being than those less associated with well-being (e.g., kindness or love of learning) has received empirical support in experimental studies (Proyer, Ruch, \& Buschor, 2013). Further empirical support for this idea can be drawn from quasi-experimental analyses: Proyer and colleagues (2015) randomly assigned participants to two conditions: Participants trained their signature strengths (i.e., the highest ranking five strengths), or their "lesser" strengths (i.e., the lowest ranking five strengths). For purposes of the present article, we reanalyzed the data $(N=238)$, and examined whether increases in well-being depended on what strengths were trained (irrespective of the condition). Results showed that increases in well-being from pretest to posttest were positively correlated with the strength's relationship to well-being, $r(22)=.43, p=.022^{1}$, suggesting that those people who trained strengths with stronger relationships with well-being benefited more from the training. In summary, we conclude that larger benefits might be expected when selecting strengths that correlate most strongly with well-being. Future experimental studies that randomly assign people to practicing one of the 24 character strengths, regardless of their baseline scores, might offer further insight in this question.

A noteworthy reminder here is we are emphasizing the outcome of well-being. If the outcome was changed (e.g., achievement, physical health), the constellation of effective

\footnotetext{
${ }^{1}$ Rank-order correlations (one-tailed) across 23 character strengths (spirituality was not included in the training program). The relationships of character strengths to well-being were taken from Ruch et al. (2010).
} 
character strengths might change. For example, strengths such as love of learning and perseverance have been especially relevant for school achievement (Wagner \& Ruch, 2015), while strengths such as love, or kindness showed robust relationships to friendships in the classroom (Wagner, 2018). Further studies on different contexts (e.g., parenting, health, or psychotherapy) would help for gaining more insights on this issue. The cross-sectional relationships of character strengths to these outcomes might serve to provide guidelines for what strengths to select in an intervention (e.g., Wagner, Gander, Proyer \& Ruch, 2019).

\section{What is the role of signature strengths?}

Signature strengths interventions have more empirical support for boosting well-being, enhancing flourishing, and lowering depression than any generic strengths intervention (Schutte \& Malouff, 2018). It makes logical sense that individuals working on signature strengths -which are naturally energizing and authentic - would experience more gains across different outcomes than working on middle/lower strengths. One study, however, found a signature strengths and lower strengths intervention to be equal to one another (e.g., Proyer et al., 2015). Thus, there are many nuances of interventions with signature strengths and other strengths subsets to be understood. For example, we are unaware of any longitudinal intervention studies in which participants focus on character strengths subsets for an extended period of time. Such a study would allow not only for a close comparison of character strengths subsets but also an examination of the maintenance of such strengths use over long periods of time.

However, in a cross-sectional study in the work context comparing signature, lower, and the five strengths most strongly correlated with happiness, it was signature strengths that had the highest unique contribution to work performance, organizational citizenship behavior, and less counterproductive work behavior, while it was the five strengths most strongly correlated with 
happiness that had the highest unique contribution to work meaningfulness, engagement, and job satisfaction (Littman-Ovadia, Lavy, \& Boiman-Meshita, 2017). Another study examined the role of signature strengths, the five strengths most strongly correlated with happiness, and demanded strengths (those strengths expected by the workplace) and found that the "fit" of signature strengths with the person's job was the most important predictor of a range of work-related outcomes, along with the specific strengths of teamwork and creativity (Harzer, Mubashar, \& Dubreuil, 2017). These findings suggest that different subsets of character strengths (e.g., signature strengths, the five strengths most strongly correlated with happiness) may provide greater value for particular outcomes.

Intervention studies that systematically vary the trained strengths and other potentially moderating factors (e.g., self-selecting vs. prescribing the strength) will provide further insight into the role of signature strengths. Another issue to be disentangled is whether working on middle strengths (those that appear in the middle of a person's profile between signature and lower strengths) or lower strengths, would be as effective in the long run as signature strengths.

A final issue to raise is the method of identification of signature strengths, which most typically is done using the highest scores in the VIA-IS. While this might be a helpful approximation for research and practical purposes, it is at best a proxy for the attributes of a signature strength as described by Peterson and Seligman (2004; e.g., having a sense of ownership or intrinsic motivation to use a strength). Measures have recently been developed that specifically use the language of signature strengths called the Global Assessment of Character Strengths and the Signature Strengths Survey (McGrath, 2019). The latter is distinctive in that it specifically describes signature strengths and asks the respondent to identify which strengths are 
signature. Future studies might compare interventions based on high-scoring strengths with those of strengths identified as signature.

\section{Do strengths-based interventions change the level of character strengths?}

Most studies so far have examined effects on well-being; the effect of interventions on strengths themselves has received limited attention. The implicit rationale for strengths-based interventions is that the exercises increase the display of strength-concordant behavior that might result in an increase in the actual strength (i.e., the trait) over time, and increases in well-being. While this increase in strength behavior has often been suggested as one of the working mechanisms of interventions (e.g., Quinlan Swain, \& Vella-Brodrick, 2011), there is not much empirical data corroborating this assumption (with few exceptions, such as for humor: Ruch, Hofmann, Rusch, \& Stolz, 2018). Dubreuil et al. (2016) and Forest et al. (2012) conducted workplace intervention programs that asked participants to identify and use their signature strengths more often. They reported increases in strengths-concordant behavior (also called "strengths use"). However, both studies only asked about the frequency of strengths use in general rather than asking about character strengths based on the VIA Classification, so it is unclear what participants understood by "strengths". Thus, it is unclear to what extent these results can be applied to the question at hand and whether interventions increase the use of strengths-concordant behavior, or operate by other mechanisms.

Changes in (trait) character strengths have - to the best of our knowledge - not been examined so far in the context of positive psychology interventions. An ideal study for addressing this would use a strengths-based intervention of high intensity and duration so that potential changes in behavior and character have enough time to unfold.

\section{How can you justify strengths-based interventions?}


Based on an analysis of several reviews and meta-analyses of positive interventions, Niemiec (2018) developed a framework to outline seven types of evidence that can be used to justify a strengths-based intervention.

1. A controlled intervention study. Several interventions have been examined in controlled intervention studies (i.e., comparing the effects of the intervention to a control condition such as a placebo, waitlist, or treatment-as-usual condition). Examples include using $a$ signature strength in new ways (Schutte \& Malouff, 2018).

2. Varying a character strengths-based intervention from a controlled intervention study. One way to vary an intervention would involve changing the instructions. For example, the intervention holistic strengths use (Niemiec, 2018) is a variant of the using a signature strength in a new way intervention focusing on signature strength use (e.g., use it with others).

3. Adding character strengths to an intervention from a controlled study. For example, a character strengths-based variant of the best possible selves intervention (Loveday, Lovell, \& Jones, 2018) could weave in strengths, asking how they will use their character strengths to reach their best selves.

4. An intervention described in scholarly publications on character strengths. Some positive interventions have been described but have not yet been evaluated in a controlled trial. One example is the intervention "turn your character strengths to be other-oriented" (VeldoraleBrogan, Bradford, \& Vail, 2010).

5. An intervention extrapolated from an observational study. A strong observational study can lay the foundation for potential interventions. For example, Kashdan and colleagues (2018) found relationships between character strengths and relationship satisfaction among couples. 
Their findings could suggest an intervention in which partners in a couple recognize and appreciate each other's top strengths (Niemiec, 2018).

\section{An intervention extrapolated from a theoretical discussion of character strengths. A} popular construct in literature on character strengths is strength overuse (e.g., Freidlin, LittmanOvadia, \& Niemiec, 2017). Niemiec (2018) described an intervention, "managing character strengths overuse," in which individuals are trained to reduce reliance on overused strengths.

\section{A character strengths intervention used in a broader program that has research} support. One example is the Character Strengths $360^{\circ}$ activity, which is used as a technique within mindfulness-based strengths practice (Niemiec, 2014). This intervention involves the participant gathering feedback from several people in their life about the participant's highest strengths.

\section{Conclusions}

The literature on strengths-based interventions is both surprisingly large and surprisingly embryonic. In part, this paradox reflects the complexity of character strengths as a construct. With a dominant model consisting of 24 dimensions, character strengths also represent an open construct that allows for almost unlimited expansion. Niemiec (2018) has also demonstrated a tremendous variety of techniques that focus on or involve character strengths. No matter how expansive the literature, then, there will remain questions unanswered or insufficiently addressed. As a contribution to encouraging more research on this topic, we have made the following points, which we will now relate to each other. Literature is still insufficient to conclude whether generic or personalized interventions are superior. In particular, it is unclear whether interventions should focus on a specific subset of strengths, which would argue for a more generic approach to intervention. Signature strengths have been a particularly common 
focus for personalized intervention studies. A recent meta-analysis (Schutte \& Malouff, 2018) reveals significant positive relationships with well-being, yet evidence is insufficient to support the superiority of this approach over other types of strengths-based interventions and when and in what context it is best to deploy a given set of strengths. It is also yet unclear whether the benefits of strength-based interventions are mediated by increased strengths use, as is widely assumed.

Finally, many interventions are theoretically promising, but many aspects, such as the relevant working mechanisms, have not yet been subjected to rigorous evaluation. Also, much of the literature on strengths-based interventions has relied on samples with a pre-existing interest in character strengths, and focused primarily on aspects of well-being as main outcomes of interest. Much work remains to be done, but so does the potential for a positively based system of intervention as an alternative to more traditional deficit-based strategies. 


\section{References}

Dubreuil, P., Forest, J., Gillet, N., Fernet, C., Thibault-Landry, A., Crevier-Braud, L., \& Girouard, S. (2016). Facilitating well-being and performance through the development of strengths at work: Results from an intervention program. International Journal of Applied Positive Psychology, 1, 1-19. https://doi.org/10.1007/s41042-016-0001-8

Forest, J., Mageau, G. A., Crevier-Braud, L., Bergeron, É., Dubreuil, P., \& Lavigne, G. L. (2012). Harmonious passion as an explanation of the relation between signature strengths' use and well-being at work: Test of an intervention program. Human Relations, 65, 1233-1252. https://doi.org/10.1177/0018726711433134

Freidlin, P., Littman-Ovadia, H., \& Niemiec, R. M. (2017). Positive psychopathology: Social anxiety via character strengths underuse and overuse. Personality and Individual Differences, 108, 50-54. http://doi.org/10.1016/j.paid.2016.12.003

Gander, F., Proyer, R. T., Ruch, W., \& Wyss, T. (2013). Strength-based positive interventions: Further evidence for their potential in enhancing well-being and alleviating depression. Journal of Happiness Studies, 14, 1241-1259. http://doi.org/10.1007/s10902-012-9380-0

Harzer, C., Mubashar T., \& Dubreuil P. (2017). Character strengths and strength-related personjob fit as predictors of work-related wellbeing, job performance, and workplace deviance. Wirtschaftspsychologie, 19(3), 23-38.

Kashdan, T. B., Blalock, D. V., Young, K. C., Machell, K. A., Monfort, S. S., McKnight, P. E., \& Ferssizidis, P. (2018). Personality strengths in romantic relationships: Measuring perceptions of benefits and costs and their impact on personal and relational well-being. Psychological Assessment, 30, 241-258. http://dx.doi.org/10.1037/pas0000464 
Linkins, M., Niemiec, R. M., Gillham, J., \& Mayerson, D. (2015). Through the lens of strength: A framework for educating the heart. Journal of Positive Psychology, 10, 64-68. https://doi.org/10.1080/17439760.2014.888581

Littman-Ovadia, H., Lavy, S., \& Boiman-Meshita, M. (2017). When theory and research collide: Examining correlates of signature strengths use at work. Journal of Happiness Studies, 18(2), 527-548. https://doi.org/10.1007/s10902-016-9739-8

Loveday, P. M., Lovell, G. P., \& Jones, C. M. (2018). The best possible selves intervention: A review of the literature to evaluate efficacy and guide future research. Journal of Happiness Studies, 19. https://doi.org/10.1007/s10902-016-9824-z

McGrath, R. E. (2019). Technical report: The VIA Assessment Suite for Adults: Development and initial evaluation (rev. ed.). Cincinnati, OH: VIA Institute on Character. Retrieved from https://evada-assets.global.ssl.fastly.net/76d1ea39-a4eb-4270-b9dc899653415f8f/assets/Technical\%20Report\%20Revised\%20Edition\%202019_1.pdf

Mongrain, M., \& Anselmo-Matthews, T. (2012). Do positive psychology exercises work? A replication of Seligman et al. (2005). Journal of Clinical Psychology, 68, 382-389. https://doi.org/10.1002/jclp.21839

National Institute of Mental Health. (2015). National Institute of Mental Health Strategic Plan for Research (DHHS Publication No. 15-6368). Available from: http://www.nimh.nih.gov/about/strategic-planning-reports/index.shtml

Ng, M. Y., \& Weisz, J. R. (2016). Annual research review: Building a science of personalized intervention for youth mental health. Journal of Child Psychology and Psychiatry, 57, 216-236. https://doi.org/10.1111/jcpp.12470 
Niemiec, R. M. (2014). Mindfulness and character strengths: A practical guide to flourishing: Boston: Hogrefe.

Niemiec, R. M. (2018). Character strengths interventions: A field guide for practitioners. Boston: Hogrefe.

Park, N., Peterson, C., \& Seligman, M. E. P. (2004). Strengths of character and well-being. Journal of Social and Clinical Psychology, 23, 603-619. https://doi.org/10.1521/jscp.23.5.603.50748

Peterson, C., \& Seligman, M. E. P. (2004). Character strengths and virtues: A handbook and classification. Oxford, UK: Oxford University Press.

Proyer, R. T., Gander, F., Wellenzohn, S., \& Ruch, W. (2015). Strengths-based positive psychology interventions: a randomized placebo-controlled online trial on long-term effects for a signature strengths- vs. a lesser strengths-intervention. Frontiers in Psychology, 6. https://doi.org/10.3389/fpsyg.2015.00456

Proyer, R. T., Ruch, W., \& Buschor, C. (2013). Testing strengths-based interventions: A preliminary study on the effectiveness of a program targeting curiosity, gratitude, hope, humor, and zest for enhancing life satisfaction. Journal of Happiness Studies, 14, 275292. https://doi.org/10.1007/s10902-012-9331-9

Quinlan, D., Swain, N., \& Vella-Brodrick, D. A. (2011). Character strengths interventions: Building on what we know for improved outcomes. Journal of Happiness Studies, 13, 145-1163. https://doi.org/10.1007/s10902-011-9311-5

Ruch, W. F., Hofmann, J., Rusch, S., \& Stolz, H. (2018). Training the sense of humor with the 7 Humor Habits Program and satisfaction with life. HUMOR, 31, 287-309. https://doi.org/10.1515/humor-2017-0099 
Ruch, W., Proyer, R. T., Harzer, C., Park, N., Peterson, C., \& Seligman, M. E. P. (2010). Values in action inventory of strengths (VIA-IS): Adaptation and validation of the German version and the development of a peer-rating form. Journal of Individual Differences, 31, 138-149. https://doi.org/10.1027/1614-0001/a000022

Schutte, N. S., \& Malouff, J. M. (2018). The impact of signature character strengths interventions: A meta-analysis. Journal of Happiness Studies. https://doi.org/10.1007/s10902-018-9990-2

Seligman, M. E. P., Steen, T. A., Park, N., \& Peterson, C. (2005). Positive psychology progress: Empirical validation of interventions. American Psychologist, 60, 410-421. http://doi.org/10.1037/0003-066X.60.5.410

Veldorale-Brogan, A., Bradford, K., \& Vail, A. (2010). Marital virtues and their relationship to individual functioning, communication, and relationship adjustment. Journal of Positive Psychology, 5, 281-293. http://doi.org/10.1080/17439760.2010.498617

Wagner, L. (2018). Good character is what we look for in a friend: Character strengths are positively related to peer acceptance and friendship quality in early adolescents. The Journal of Early Adolescence, 0272431618791286. https://doi.org/10.1177/0272431618791286

Wagner, L., Gander, F., Proyer, R.T. \& Ruch, W. (2019). Character strengths and PERMA: Investigating the relationships of character strengths with a multidimensional framework of well-being. Applied Research in Quality of Life. https://doi.org/10.1007/s11482-018-9695-z 
Wagner, L., \& Ruch, W. (2015). Good character at school: positive classroom behavior mediates the link between character strengths and school achievement. Frontiers in Psychology, 610. https://doi.org/10.3389/fpsyg.2015.00610 